\title{
Distinguishing of Stable Genotypes and Mega Environment for Grain Yield Performance of Sorghum [Sorghum bicolor (L.) Moench] Genotypes Using Spatial Analysis
}

\author{
Kidanemaryam Wagaw ${ }^{1 *}$, Amare Seyoum ${ }^{1}$, Taye Tadesse ${ }^{2}$, Amare Nega $^{3}$, \\ Adane Gebreyohannes4, Tamirat Bejiga1, Sewmehon Siraw1, Hailemariam Solomon1, \\ Daniel Nadew ${ }^{5}$, Meron Bogale ${ }^{1}$ \\ ${ }^{1}$ Melkassa Agricultural Research Center, Ethiopian Institute of Agricultural Research, Adama, Ethiopia \\ ${ }^{2}$ Crop Research Directorate, Ethiopian Institute of Agricultural Research, Addis Ababa, Ethiopia \\ ${ }^{3}$ Department of Cellular, Microbial and Molecular Biology, College of Natural Science, Addis Ababa University, Addis Ababa, \\ Ethiopia \\ ${ }^{4}$ School of Agricultural, Earth and Environmental Sciences, College of Agriculture, Engineering and Science, University of \\ KwaZulu-Natal, Pietermaritzburg, South Africa \\ ${ }^{5}$ School of Plant Sciences, College of Agriculture and Environmental Sciences, Haramaya University, Dire Dawa, Ethiopia \\ Email: *kidanwagaw@gmail.com
}

How to cite this paper: Wagaw, K., Seyoum, A., Tadesse, T., Nega, A., Gebreyohannes, A., Bejiga, T., Siraw, S., Solomon, H., Nadew, D. and Bogale, M. (2021) Distinguishing of Stable Genotypes and Mega Environment for Grain Yield Performance of Sorghum [Sorghum bicolor (L.) Moench] Genotypes Using Spatial Analysis. American Journal of Plant Sciences, 12, 417-431. https://doi.org/10.4236/ajps.2021.123027

Received: January 14, 2021

Accepted: March 28, 2021

Published: March 31, 2021

Copyright ( 2021 by author(s) and Scientific Research Publishing Inc. This work is licensed under the Creative Commons Attribution International License (CC BY 4.0).

http://creativecommons.org/licenses/by/4.0/ (c) (i) Open Access

\begin{abstract}
Sorghum is a staple food crop in Ethiopia and its production is mainly constrained by drought, other environmental factors, and the use of low-yielding, local sorghum varieties. To improve sorghum productivity, it is crucial to provide farmers with high yielding, stable sorghum cultivars that are tolerant to drought and other constraints. The stable performance of sorghum varieties in a growing region is critical to obtain a high and stable yield. In the 2012-2014 crop year, 24 genotypes, including standard controls, were evaluated at the national variety trial stage over six main dry lowland sorghum growing sites and two years made 7 environments to evaluate their performance, stability and to quantify Genotype by Environment Interaction (GEI) across moisture stress sorghum growing areas of Ethiopia. Spatial modeling has been used to estimate predicted mean (BLUPs) results and Performance and estimation of environmental correlation, heritability, GEI, and other parameters using the ASReml3-R analysis package. The predicted mean yield of the test genotypes across the environment ranged from 3.45 to $1.56 \mathrm{t} \cdot \mathrm{ha}^{-1}$. Based on the result genotype G13, it could be further promoted because of its yield advantage and other important attributes over the standard checks, but it is the least stable. Based on the analyzed result, two mega environments
\end{abstract}


were formed and Environment 1 (E1) is identified as an ideal environment among the testing environments.

\section{Keywords}

Genetic Correlation, Mega Environment, Stability, Spatial Analysis

\section{Introduction}

Sorghum is a food, fuel, forage and feed cereal crop well-matched to drought-prone areas for $500 \mathrm{M}$ of the world's poorest people. Its African originated small diploid genome and phenotypic diversity make it the ideal $\mathrm{C} 4$ grass model to complement C3 crop [1] [2] and [3]. It is an extremely productive, drought tolerant $\mathrm{C}_{4}$ grass grown mostly for grain, forage, sugar and biomass cultivation [4]. It has a chromosome number of $2 \mathrm{n}=20$ with $\sim 730 \mathrm{Mb}$ [5] genome size. Sorghum is predominantly self-pollinated, short-term crop with a cross-pollination rate of up to $30 \%$ depending on the nature of the panicles. This is a common crop of Ethiopia primarily grown with low rainfall zones, poor soil productivity and high temperature conditions in highly varying locations. Sorghum is considered as main food security crop in Ethiopia which is contributive $18 \%$ of the whole grain production. In Ethiopia, sorghum grows from lowland areas with decreased rainfall and elevated altitude temperatures marked by low temperatures and higher rates of rainfall [6]. Sorghum is the world's fifth largest cereal crop and third largest dry land crop in Ethiopia cultivated by $6 \mathrm{M}$ smallholder farmers in over 1.9 M hectares of land with $25 \%$ area coverage from cereal crops and sorghum contributed $17 \%$ of cereal production (Maize, Teff and Wheat) which is about 51.7 M quintals of production [7]. Globally, sorghum is the significant source of animal feed and forage, an evolving biofuel crop and a C4 grass model, especially genetically complex sugar cane. Full utilization of the potential of sorghum involves an awareness of genetic diversity at the gene level and the need to establish genetic diversity in order to obtain essential varieties that could have high yields and preferences for end-users, particularly farmers and commercial sectors.

Improving high yielding and stable sorghum varieties is a key factor in the interaction between farmers and the personal seed sector and the commercialization of sorghum in Ethiopia [8]. In Ethiopia, sorghum breeding has been mostly restrained to germplasm characterization using phenotypic traits and exotic sorghum hybrid parental lines. There is also an increment in developing elite lines from the local available sorghum lines. Research on sorghum variety development targeted the dry lowland sorghum growing areas is currently hosting ample amount of elite lines developed from national sorghum research program through successive pedigree crossing program and now a time there are many varietal experiments which planned to evaluate their grain yield performance 
and stability in the areas where sorghum is grown mainly. One of the best strategies to cope up with the limiting factor for sorghum production can be tackled by developing offspring from the gene pool which are found locally where the business will be done.

Because of the inherent capacity to adapt the limited moisture available and serve the farming community for multi-purposes, sorghum is the dominant cereal crop in the dry lowland area. Hence, the national program has given more emphasis and much resource has been exerted to generate varieties for the dry lowland areas. Use of genetic variability is the most important tool in plant breeding, and this must be generalized by phenotypic expression. The issues of the phenotypic variation depend largely on the environment where it is growing [9]. This variation is further complicated by the fact that not all genotypes respond in similar ways to the change in environment and season. If the performance of genotypes is different at various environments, then GEI becomes a major challenge to crop betterment. Genotype by environment interaction is the variation, coming up from the lack of agreement between the genetic and non-genetic effects in multi-location experiments. So, the national sorghum research program in Ethiopia is developing and evaluating many elite lines across sorghum growing areas over years. So, in order to confirm the developed inbred lines, whether they are adapted and performing good or not, varietal experiments across environments over location and year need to be planned and executed. Hence, in 2012-2014 (a total of 24 advanced lines including 2 released checks) were evaluated as at national variety trial stage over six main sorghum growing dry lowland sites and two years which make 7 environments in order to evaluate their performance and stability across moisture stress sorghum growing areas of Ethiopia. The objective of this experiment was, therefore, to identify stable genotypes, mega environments, and high yield and adaptable, early maturing sorghum genotype using the spatial analysis across dry lowland sorghum growing areas.

\section{Materials and Methods}

The site description is stated in the following Table 1.

Table 1. Description of testing environments.

\begin{tabular}{cccccccc}
\hline Location & Longitude Latitude & $\begin{array}{c}\text { Altitude } \\
\text { (m.a.s.l) }\end{array}$ & Soil type & $\begin{array}{c}\text { Rainfall in } \\
\mathrm{mm}\end{array}$ & $\begin{array}{c}\text { Minimum } \\
\mathrm{T}^{\circ} \mathrm{C}\end{array}$ & $\begin{array}{c}\text { Maximum } \\
\mathrm{T}^{\circ} \mathrm{C}\end{array}$ \\
\hline Kobo & $39^{\circ} 38^{\prime} \mathrm{E}$ & $12^{\circ} 09^{\prime} \mathrm{N}$ & 1513 & Vertisol & 678 & 14.8 & 32 \\
Miesso & $39^{\circ} 21^{\prime} \mathrm{E}$ & $8^{\circ} 30^{\prime} \mathrm{N}$ & 1470 & Vertisol & 571 & 16 & 31 \\
Melkassa & $39^{\circ} 9^{\prime} \mathrm{E}$ & $14^{\circ} 6^{\prime} \mathrm{N}$ & 1550 & Vertisol & 615 & 20.4 & 34 \\
Shewarobit & $39^{\circ} 93^{\prime} \mathrm{E}$ & $10^{\circ} 35^{\prime} \mathrm{N}$ & 1500 & Vertisol & 713 & 17.7 & 33 \\
Mehoni & $39^{\circ} 68^{\prime} \mathrm{E}$ & $12^{\circ} 51^{\prime} \mathrm{N}$ & 1574 & Vertisol & $300-750$ & 18 & 25 \\
Babilie & $42^{\circ} 20^{\prime} \mathrm{E}$ & $9^{\circ} 13^{\prime} \mathrm{N}$ & 1556 & loam & 778 & 16 & 31
\end{tabular}

Source: Center profile assessed from each center. 


\subsection{Experimental Genotypes, Statistical Design, and Data Collection}

A total of 24 sorghum inbred lines (Table 2) including 2 popular recently released variety (Melkam and Teshale) as a standard check were evaluated over 6 dry lowland sorghum growing areas of Ethiopia in 2012-2014 cropping year which makes 7 testing environments and in 2012 it was done at two locations (Miesso and Melkassa) (Table 1). The advanced lines were developed by National Sorghum research Program through pedigree crossing method at Melkassa agricultural research center and advanced through successive evaluation and selection for their grain yield performance and stability under moisture stressed sorghum growing areas of Ethiopia. All the advanced lines were evaluated for their yield, over all agronomic performance and other farmers' preferential attributes.

Table 2. List and description of genetic materials.

\begin{tabular}{|c|c|c|c|c|}
\hline Entry & G_Code & Genotype & Pedigree & Remark \\
\hline 1 & G1 & 2351 & $((\mathrm{~S} 35 / \mathrm{B} 35) / \mathrm{S} 35)$ & Lines \\
\hline 2 & G2 & 2354 & $((\mathrm{~S} 35 / \mathrm{B} 35) / \mathrm{S} 35)$ & Lines \\
\hline 3 & G3 & 2372 & $((\mathrm{~S} 35 / \mathrm{B} 35) / \mathrm{S} 35)$ & Lines \\
\hline 4 & G4 & 2414 & $((\mathrm{~S} 35 / \mathrm{B} 35) / \mathrm{S} 35)$ & Lines \\
\hline 5 & G5 & 2420 & $((\mathrm{~S} 35 / \mathrm{B} 35) / \mathrm{S} 35)$ & Lines \\
\hline 6 & G6 & 2429 & $((\mathrm{~S} 35 / \mathrm{B} 35) / \mathrm{S} 35)$ & Lines \\
\hline 7 & G7 & 2494 & ((ICSV111/B35)/ICSV111) & Lines \\
\hline 8 & G8 & 2500 & ((ICSV111/B35)/ICSV111) & Lines \\
\hline 9 & G9 & 2505 & ((ICSV111/B35)/ICSV111) & Lines \\
\hline 10 & G10 & 2523 & ((ICSV111/B35)/ICSV111) & Lines \\
\hline 11 & G11 & 2549 & ((ICSV111/B35)/ICSV111) & Lines \\
\hline 12 & G12 & 2560 & ((ICSV111/B35)/ICSV111) & Lines \\
\hline 13 & G13 & 2620 & ((ICSV111/B35)/ICSV111) & Lines \\
\hline 14 & G14 & 2638 & ((ICSV111/B35)/ICSV111) & Lines \\
\hline 15 & G15 & 679 & IDSG06134 & Lines \\
\hline 16 & G16 & 682 & IDSG06135 & Lines \\
\hline 17 & G17 & 686 & IDSG06136 & Lines \\
\hline 18 & G18 & 615 & IDSG061116 & Lines \\
\hline 19 & G19 & DoradoISIAPDorado & DoradoISIAPDorado & Lines \\
\hline 20 & G20 & ICSV111 & ICSV111 & Recurrent parent \\
\hline 21 & G21 & S35 & S35 & Recurrent parent \\
\hline 22 & G22 & B35 & B35(IS40653) & Recurrent parent \\
\hline 23 & G23 & Teshale & $3443-2-\mathrm{OP}$ & Check \\
\hline 24 & G24 & Melkam & WSV387 & Check \\
\hline
\end{tabular}


The experiment was conducted at Mieso, Melkassa, Shewarobit, Kobo, Babilie and Mehoni during 2012-2014 cropping seasons. Row column Design was used to lay out the experiment with two replications in a row column arrangement to minimize the spatial variability (trends) in estimating the genetic value. Each plot contained three rows of $3 \mathrm{~m}$ length separated by $0.75 \mathrm{~m}$. At all locations sowing was done in between last week of June to first week of July when enough rain was received. Plantation was done manually by drilling along the farrow, and population was adjusted by thinning considering $0.20 \mathrm{~m}$ as spacing between plants. NP fertilizer was applied at planting time with the rate of $100 \mathrm{~kg} / \mathrm{ha}$ and Urea was side dressed when the plant reached at knee height at $50 \mathrm{~kg} / \mathrm{ha}$ basis. Weeding was conducted at least three times during the growing period in each of the test sites depending on the level of weed infestation in the experimental field uniformly.

The following agronomic traits were collected and analyzed to identify stable and superior hybrids compared the standard check variety and hybrid.

\subsection{Days to $50 \%$ Flowering (DTF)}

The time between days to emergence to $50 \%$ of the plants in a plot reached half-bloom stage.

\subsection{Plant Height (PHT)}

The length from the base of the plant to the tip of the panicle in $\mathrm{cm}$.

\subsection{Grain Yield per Plot (GY)}

Grain yield in kilogram of plants from the three rows and adjusted to $13 \%$ moisture level and converted to qt.ha ${ }^{-1}$.

\subsection{Plant Aspect (PAS)}

Over all agronomic desirability score (drought tolerance, earliness, head exertion and compactness, grain size and shape, thresh ability, disease and insect resistance, etc.) was scored using $1-5$ score where $1=$ excellent and $5=$ poor.

\subsection{Statistical Investigation}

The concurrence of genotypes between testing environments was used to check as of the trial series could be analyzed as a single META as of each trial consisting similar test entries, which is the current best practice method for analyzing field trials for plant breeding programs [10]. The MET for sorghum advanced lines included 24 candidate lines including recently released varieties as standard check and executed in seven testing environments of six sites over three years and in 2012 at two sites (Miesso and Melkassa). Spatial effects were fitted to each trial and then a variance structure was created to produce correlations between trials (testing environments) in a factor analytic (FA) framework [10]. Heritability (repeatability) estimates on a line mean basis were cal- 
culated for the testing environments (trials) groups according to the method proposed by [11].

For each analyzed trait, the genotype $\times$ environment $(G \times E)$ interactions were considered. These interactions were created by considering a pair-wise correlation matrix for the correlations of each pair of testing environments (trials). The analysis results in a genetic variance for each trial along with a set of loadings that represent FA frameworks that can be used to recreate the correlation matrix [10]. The genetic correlations between the testing environments at each of testing environments were identified, with a mean genetic correlation between the testing environments.

Equation for the mixed linear model that ASReml fits using ReML is

$$
Y=X \tau+Z u+\eta,
$$

where; $Y$ is the $(n \times 1)$ observation vector, $n=$ total number of experimental plots, $X$ is the $(n \times p)$ design matrix for fixed effects, $\tau$ is the $(p \times 1)$ vector of $p$ fixed effects, $Z$ is the $(n \times q)$ design matrix for random effects, $u$ is the $(q \times 1)$ vector for $q$ random effects, $\eta$ is the $(n \times 1)$ vector of residuals [12].

\section{Results and Discussion}

\subsection{Genetic Performance, Variance and Heritability of Genotypes over Locations}

The mean performance of the 24 genotypes including the standard checks for grain yield (GY) is presented in Table 2 . The mean grain yield of the test genotypes across environment was ranged between 3.45 to $1.56 \mathrm{t} \cdot \mathrm{ha}^{-1}$. In comparison to the high performed standard check variety (G24) nine of the test entries gave the highest mean grain yield advantage ranged between 3.45 to $3.21 \mathrm{t} \cdot \mathrm{ha}^{-1}$ or $(8.2 \%-0.63 \%)$ respectively (Table 3$)$. The highest performed genotype across all the environments is G13 with grain yield of $3.45 \mathrm{t} \cdot \mathrm{ha}^{-1}$.

The GE variability in this analysis was attributed to predicted factors (location) and estimated factors (years). Throughout this analysis, GE may be related to different variables such as surface types, weather levels and temperatures. The economical choice is to cultivate sorghum varieties that are suited to the target climate. However, the areas do not have well specified borders and farmers have to control each individual variety with wide adaptability, rather than location-specific varieties, is strongly assisted by each other in the selection of the variety which is produced.

Since heritability is a measure, its numerical meaning varies from 0.0 (genes do not relate at all to phenotypic individual differences) to 1.0 (genes are the sole explanation for individual differences). In this study grain yield was highly heritable $(>60 \%)$ as per scale described by [13] in individual environments. Grain yield is highly heritable in E5 followed by E2, E6 and E1 (Table 3). High estimates of heritability in broad sense were obtained for yield is in line with obtained by [14]. 
Table 3. Mean performance, variance, and heritability of the genotypes using spatial analysis.

\begin{tabular}{|c|c|c|c|c|c|c|c|c|}
\hline \multirow{2}{*}{ Genotypes } & \multicolumn{8}{|c|}{ BLUP_Grain yield } \\
\hline & E1 & E2 & E3 & E4 & E5 & E6 & E7 & Average \\
\hline G1 & 1.16 & 3.87 & 4.68 & 2.56 & 2.48 & 2.57 & 5.57 & 3.27 \\
\hline G2 & 1.07 & 3.47 & 4.30 & 2.56 & 2.22 & 2.41 & 5.50 & 3.07 \\
\hline G3 & 1.12 & 3.72 & 4.74 & 2.77 & 2.39 & 2.58 & 5.75 & 3.30 \\
\hline G4 & 1.19 & 3.99 & 4.84 & 2.74 & 2.56 & 2.61 & 5.56 & 3.36 \\
\hline G5 & 1.11 & 3.56 & 5.73 & 2.51 & 2.26 & 2.28 & 5.03 & 3.21 \\
\hline G6 & 0.94 & 2.88 & 3.62 & 2.51 & 1.84 & 2.14 & 5.32 & 2.75 \\
\hline G7 & 1.10 & 3.64 & 5.38 & 2.73 & 2.34 & 2.56 & 5.76 & 3.36 \\
\hline G8 & 1.10 & 3.55 & 4.79 & 2.32 & 2.25 & 2.25 & 4.93 & 3.03 \\
\hline G9 & 1.19 & 3.97 & 4.61 & 2.75 & 2.54 & 2.59 & 5.51 & 3.31 \\
\hline G10 & 1.06 & 3.37 & 4.20 & 2.49 & 2.14 & 2.24 & 5.11 & 2.94 \\
\hline G11 & 1.02 & 3.11 & 2.72 & 2.16 & 1.96 & 1.99 & 4.60 & 2.51 \\
\hline G12 & 1.00 & 3.22 & 3.98 & 2.61 & 2.06 & 2.35 & 5.59 & 2.97 \\
\hline G13 & 1.15 & 3.83 & 6.22 & 2.47 & 2.45 & 2.53 & 5.47 & 3.45 \\
\hline G14 & 1.09 & 3.63 & 4.63 & 2.79 & 2.34 & 2.65 & 6.04 & 3.31 \\
\hline G15 & 0.90 & 2.68 & 3.15 & 2.15 & 1.70 & 1.98 & 5.06 & 2.52 \\
\hline G16 & 0.89 & 2.66 & 3.93 & 2.48 & 1.69 & 2.02 & 5.19 & 2.69 \\
\hline G17 & 0.91 & 2.77 & 3.73 & 2.41 & 1.77 & 2.12 & 5.36 & 2.73 \\
\hline G18 & 0.97 & 2.89 & 4.13 & 1.91 & 1.81 & 1.85 & 4.41 & 2.57 \\
\hline G19 & 0.68 & 1.50 & 2.42 & 1.42 & 0.87 & 0.92 & 3.11 & 1.56 \\
\hline G20 & 0.99 & 3.09 & 3.97 & 2.46 & 1.97 & 2.19 & 5.25 & 2.85 \\
\hline G21 & 1.12 & 3.67 & 4.19 & 2.47 & 2.34 & 2.41 & 5.30 & 3.07 \\
\hline G22 & 1.06 & 3.43 & 4.61 & 2.71 & 2.20 & 2.44 & 5.63 & 3.15 \\
\hline G23 & 1.13 & 3.75 & 5.12 & 2.82 & 2.41 & 2.62 & 5.83 & 3.38 \\
\hline G24 & 1.02 & 3.31 & 4.60 & 2.68 & 2.14 & 2.53 & 6.02 & 3.19 \\
\hline Mean yield & 1.04 & 3.32 & 4.35 & 2.48 & 2.15 & 2.29 & 5.29 & \\
\hline$\sigma^{2} g$ (Genetic variance) & 0.02 & 0.36 & 0.94 & 0.14 & 0.16 & 0.16 & 0.51 & \\
\hline$\sigma^{2} \mathrm{e}$ (Error Variance) & 0.09 & 0.41 & 0.84 & 0.46 & 0.33 & 0.34 & 1.30 & \\
\hline $\mathrm{H}^{2}$ (Heritability) & 82.38 & 87.32 & 80.21 & 70.83 & 88.18 & 86.52 & 72.94 & \\
\hline
\end{tabular}

BB12SG2N02 = E1, KB13SG2N02 = E2, MH14SG2N02 = E3, MK12SG2N02 = E4, S12SG2N02 = E5, MS13SG2N02 $=$ E6, SR13SG2N02 $=$ E7, E = Environment.

\subsection{Genetic Correlation}

The spatial filed trend showed that, whether there is a variation or not between the genetic materials at each of testing environments on mean based. The yield performance of the genotypes is lower than the rest of testing environments for Babilie 2012 (BB12SG2N02) followed by Miesso 2012 (MS12SG2N02) while the highest yield record was observed for Shewarobit 2013 (SR13SG2N02) (Table 4). 
Table 4. Genetic correlation of testing environments for grain yield performance of genotypes.

\begin{tabular}{cccccccc}
\hline & E1 & E2 & E3 & E4 & E5 & E6 & E7 \\
\hline E1 & 1 & 1.0 & 0.7 & 0.6 & 1.0 & 0.8 & 0.5 \\
E2 & 1.0 & 1 & 0.7 & 0.7 & 1.0 & 0.9 & 0.6 \\
E3 & 0.7 & 0.7 & 1 & 0.5 & 0.7 & 0.6 & 0.5 \\
E4 & 0.6 & 0.7 & 0.5 & 1 & 0.7 & 0.8 & 0.8 \\
E5 & 1.0 & 1.0 & 0.7 & 0.7 & 1 & 0.9 & 0.7 \\
E6 & 0.8 & 0.9 & 0.6 & 0.8 & 0.9 & 1 & 0.9 \\
E7 & 0.5 & 0.6 & 0.5 & 0.8 & 0.7 & 0.9 & 1 \\
\hline
\end{tabular}

BB12SG2N02 = E1, KB13SG2N02 = E2, MH14SG2N02 = E3, MK12SG2N02 = E4, S12SG2N02 = E5, MS13SG2N02 $=$ E6, SR13SG2N02 $=$ E7, E $=$ Environment.

The study identified the relative genetic deserves of different lines where trials are more likely correlated (Figure 1). When trials are correlated (similar response of genotypes at some environment) selecting best materials in one environment is similar with selecting best material in another environment. In this case, MET analysis can also assist to realize the broad and specific adaptation of genotypes over a range of genetic materials. In this study, the factor analytic model was used for MET analysis. Then, the correlations between environments ranged from -1 and 1 (Figure 1 and Figure 4 ). Correlations of -1 indicated that the performance of the environments fall in opposite direction (the angle between the two environment is more than 90 degree), implying that the highest performing genotypes in one environment were the lowest performing genotypes in another environment (Figure 1). Similar finding was reported by [15] for genetic correlation among six environments based on their response for grain yield performance of sorghum genotypes.

Correlation of +1 is an indication of perfect similarity between two environments, hence selecting superior genotypes based on one environment is the same as selection for another environment [16]. For instance, Babilie 2012 (BB12SG2N02) is perfectly positively correlated with Kobo 2013 (KB13SG2N02), Miesso 2012 (MS12SG2N02) and Miesso 2013 (MS13SG2N02) and Miesso 2013 (MS13SG2N02) is perfectly positively correlated with Babilie 2012 (BB12SG2N02), Kobo 2013 (KB13SG2N02), Melkassa 2012 (MK12SG2N02), Miesso 2012 (MS12SG2N02) and Shewarobit 2013 (SR13SG2N02) and the like.

Figure 4 also describes about correlations between the trials. Environments (Trials) with less angle (less than 90 degree) between their two lines are more correlated, for example; Shewarobit 2013 (SR13SG2N02) with Melkassa 2012 (MK12SG2N02), Miesso 2013 (MS13SG2N02) and others. Then, selection of the best genotypes based on one of the two environments does not change the ranks of the genotypes in another environment. When an angle between two lines is greater than 90 degrees, selection based on the two environments can change the ranks of genotypes and doing spatial analysis is recommendable to accommodate the spatial trends. 
Genetic correlation matrix of 12-14 NVT

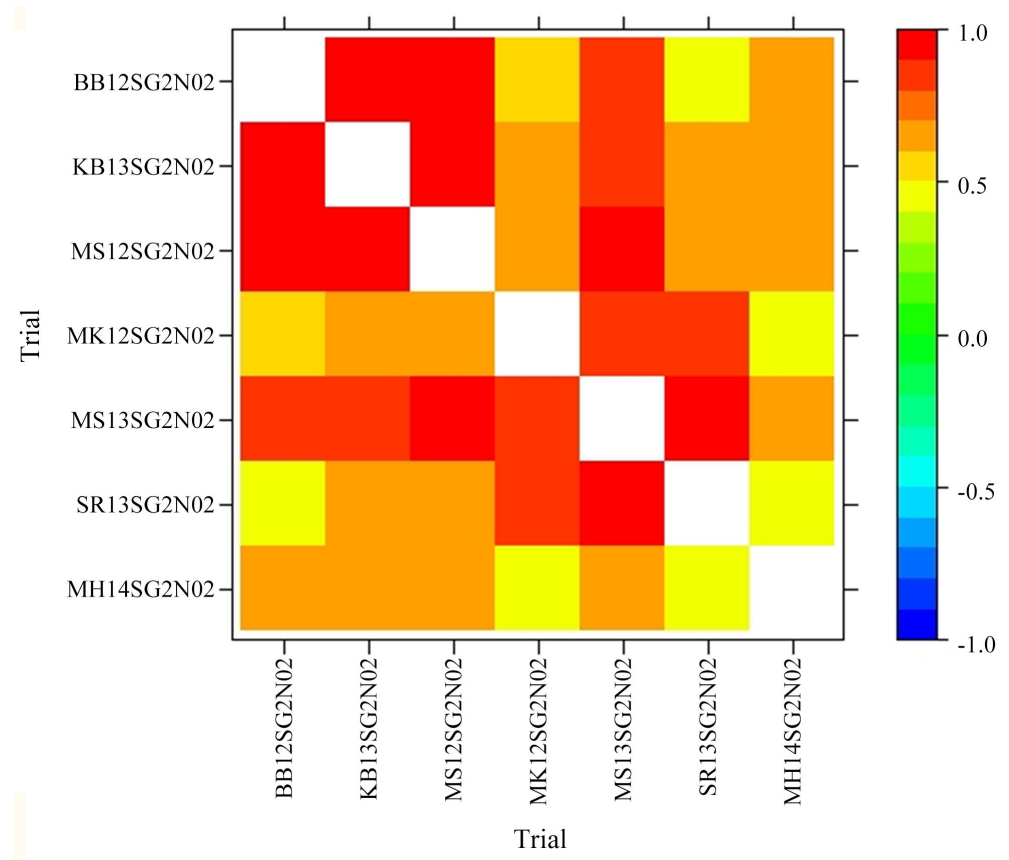

Figure 1. Genetic correlation of grain yield for testing environments. BB12SG2N02 = E1, KB13SG2N02 = E2, MH14SG2N02 = E3, MK12SG2N02 = E4, S12SG2N02 = E5, MS13SG2N02 = E6, SR13SG2N02 = E7, E = Environment.

Graphical description of MET data is commonly used to explain genotype by environment interaction (GEI). In the concepts of which genotypes won and where is exemplified. Plots show that the environment with longest line from the center measures the discriminativeness of that environment when compared with others. For example, Mehoni 2014 (MH14SG2N02) and Shewarobit 2013 (SR13SG2N02) followed by Kobo 2013 (KB13SG2N02) were among the most discriminative environments; this means these environments had considerable contributions in discriminating genetic variations. On the other hand, environments with less distances from the center were those stable environments like Babilie 2012 (BB12SG2N02), Melkassa 2012 (MK12SG2N02) followed by Miesso 2012 (MS12SG2N02) and Miesso 2013 (MS13SG2N02), hence they explained less genetic variations. In addition to this, when a specific genotype is close to a given environment, it indicates that the genotype is the winner for that specific environment. That means, that genotype is the best performer for that trial (environment) [17]. When we look at the mean performance genotype G13 (3.45 $\left.\mathrm{t} \cdot \mathrm{ha}^{-1}\right)$ is the most performed and stable genotype averagely among the testing genetic materials included.

\subsection{Test Environment and Genotype Evaluation Based on GGE Biplot Analysis}

In multi-environment trial considering both the stability and mean performance for grain yield is greatly important [18]. Likewise, in GGE biplot technique, the 
estimation of yield and stability of genotypes (Figure 2) have been carried out by way of using the average environment coordinate (AEC) strategies [19]. The line passing via the biplot origin is referred to as the average environment coordinate (AEC), that is described by way of the average PC1 and PC2 ratings for all environments [20] greater close to concentric circle shows better mean yield. The line, which passes via the origin and is perpendicular to the AEC with double arrows, represents the stableness of genotypes. Either direction away from the biplot origin, at the axis, suggests more GE interplay and decreased stability. For selection, the ideal genotypes are those with both high mean yield and high stability. Inside the biplot, they are near the origin and have the shorter vector from the AEC. Therefore, genotype G7, G16 and G10 were the most stable and genotypes G13, G5, G19 and G18 were the least stable (Figure 2).

\subsection{Which-Won-Where (Genotype-Environment Interaction and Mega Environments)}

The polygon view of GGE biplot (Figure 5) is the first-rate way for the identification of prevailing genotypes with visualizing the interplay patterns among genotypes [20] in MET analysis, which is beneficial in estimating the feasible existence of various mega environments. On this biplot, a polygon turned into shaped with the aid of connecting the vertex genotypes which are furthest score from that environment with straight lines and the rest closer of the genotypes were placed inside the polygon. The vertex genotypes had been G13, G5, G19, G14, and G11 having the biggest distance from the beginning. Those genotypes are the excellent or poorest in a few or all environments due to the fact they're furthest from the origin of biplot [20], which have been extra attentive to environmental change and are taken into consideration as particularly tailored genotypes (Figure 5). The vertex genotypes have been the most responsive genotypes, as they have got the longest distance from the beginning of their origin. Genotypes G16, G10 and some other had been placed apparently close to the biplot origin confirmed reasonably common overall performance and these genotypes have been much less conscious of environments than the vertex genotypes (Figure 5). In the present research, the partitioning of GE interaction through GGE biplot analysis confirmed that PC1 and PC2 accounted for 95.06\% of the full variance (Figure 5).

Among the test environments, E1 is the ideal environment to advance and evaluate the genetic materials (Figure 3). The ideal genotypes in terms of stability were found in the center of the contour lines and that genotype was stable across testing environments (Figure 3). From the genotypes G4, G23, G2 and G1 were found in the most centric circle and the genotypes were the most stable genotypes across the testing environments. Similar result has been reported [21].

E3, E7, and E2 were the most discriminative environments and intensive selection in these environments is most important than others. Since, the angles between the environmental angles were less than $90^{\circ}$ the environments are more likely similar and selection at one environment is similar to the others. Geno- 
types, G10 and G16 were the most stable genotypes since they are located closer to the origin Figure 4.

Mega-environment formation idea needs multi-year data, in this study two mega environments were formed (Figure 5). Thus environments, E1, E2, E3, E4, E5 and E6 formed one mega environment, E4, E6 and E7 formed the other mega environment, while E4 and E6 were the intersect for both mega environments (Figure 5). The engaging genotypes for each segment are those located at the vertex.

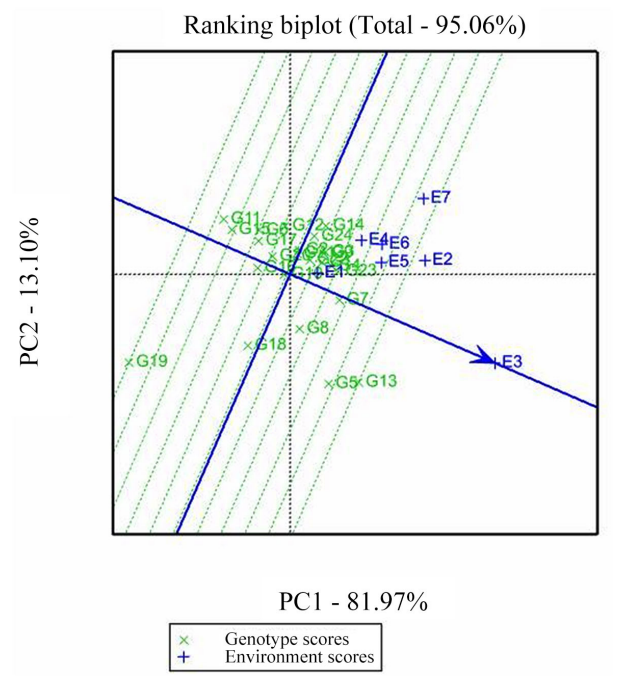

Figure 2. GGE biplot showing the ranking of genotypes for both yield and stability performance over environments. BB12SG2N02 = E1, KB13SG2N02 = E2, MH14SG2N02 = E3, MK12SG2N02 = E4, S12SG2N02 = E5, MS13SG2N02 = E6, SR13SG2N02 = E7, E = Environment.

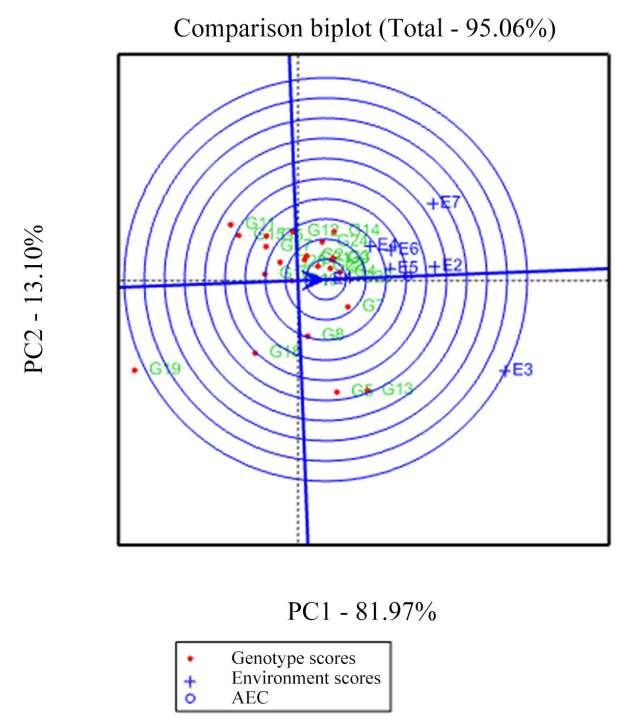

Figure 3. Comparison biplot showed ideal environment and stable genotype. BB12SG2N02 = E1, KB13SG2N02 = E2, MH14SG2N02 = E3, MK12SG2N02 = E4, S12SG2N02 = E5, MS13SG2N02 = E6, SR13SG2N02

$=\mathrm{E} 7, \mathrm{E}=$ Environment. 


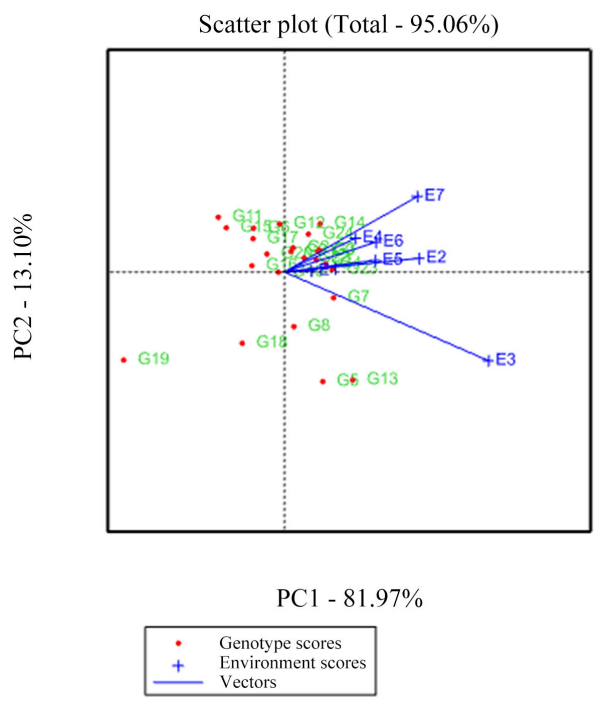

Figure 4. Scatter plot which showed discriminativeness of the testing environments. BB12SG2N02 = E1, KB13SG2N02 = E2, MH14SG2N02 = E3, MK12SG2N02 = E4, S12SG2N02 = E5, MS13SG2N02 = E6, SR13SG2N02 = E7, $\mathrm{E}=$ Environment.

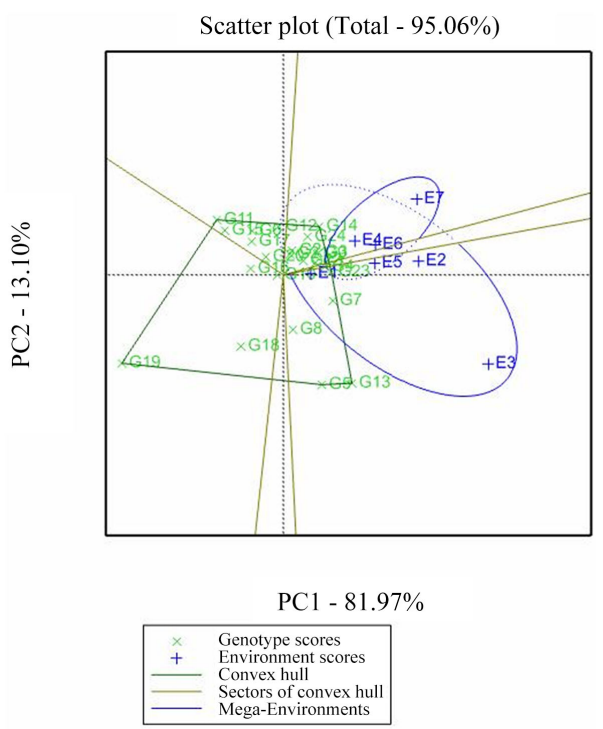

Figure 5. Mega environment and Polygon view of genotype-environment interaction over seven environments. BB12SG2N02 = E1, KB13SG2N02 = E2, MH14SG2N02 = E3, MK12SG2N02 = E4, S12SG2N02 = E5, MS13SG2N02 = E6, SR13SG2N02 = E7, E = Environment.

Adaptability of sorghum over seasons and environments has its intrinsically strength that can be nurtured through development of high yielder, drought tolerant and acceptability with farmer preferences in grain quality then facilitating supply of the new varieties will increase the adoption to the targeted areas [22].

\section{Conclusions}

Improvement of high yielding and stable performing sorghum varieties is the 
key riding element to interact the farmers and personal seed sectors and commercialize sorghum in Ethiopia. Because of the inherent capacity to adapt the limited moisture available and serve the farming community for multi-purposes, sorghum is the dominant cereal crop in the dry lowland area.

The mean grain yield of the test genotypes across environment was ranged from 3.45 to $1.56 \mathrm{t} \cdot \mathrm{ha}^{-1}$. In comparison to the high performed standard check variety, 9 of the genotypes gave the highest mean grain yield advantage ranged from 3.45 to $3.21 \mathrm{t} \cdot \mathrm{ha}^{-1}$ respectively. The highest performed genotype across all the environments is G13 with grain yield of $3.45 \mathrm{t} \cdot \mathrm{ha}^{-1}$ and this genotype was flowered earlier than the rest genotypes with predicted value of 75 days starting from sowing date and also it has good plant height to exploit if for biomass attributes. In addition to this the mentioned genotype has scored good agronomic performance including threshability, grain attributes, earliness, head exertion and other agronomic attributes.

The correlations between environments ranged from -1 to +1 . Correlation of +1 is an indication of perfect similarity between two environments, hence selecting superior genotypes based on one environment is the same as selection for another environment. Hence, Shewarobit 2013 with Melkassa 2012, Miesso 2013 and others are more correlated.

Based on the predicted mean for grain yield, genotype G13 was the highest performed genotype. Genotype G4, G23, G2 and G1 were the most stable ones. Two mega environments were formed using these environments. Thus environments, E1, E2, E3, E4, E5 and E6 formed one mega environment, E4, E6 and E7 formed the other mega environment, while E4 and E6 were the intersection for both mega environments. Also, E1 was the ideal environment.

\section{Conflicts of Interest}

The authors declare no conflicts of interest regarding the publication of this paper.

\section{References}

[1] Mace, E.S., Tai, S., Gilding, E.K., et al. (2013) Whole-Genome Sequencing Reveals Untapped Genetic Potential in Africa's Indigenous Cereal Crop Sorghum. Nature Communications, 4, Article No. 2320. https://doi.org/10.1038/ncomms3320

[2] Iqbal, M.A. and Iqbal, A. (2015) Overview on Sorghum for Food, Feed, Forage and Fodder: Opportunities and Problems in Pakistan's Perspectives. American-Eurasian Journal of Agricultural \& Environmental Sciences, 15, 1818-1826.

[3] Guade, Y.F., Mekbib, F. and Ageru, A.A. (2017) Participatory Evaluation and Selection of Lowland Sorghum (Sorghum bicolor L. Moench) Varieties: The Case of Kamashi Zone, Western Ethiopia. American-Eurasian Journal of Agricultural \& Environmental Sciences, 17, 220-226.

[4] Casto, A.L., Mckinley, B.A., Man, K., Yu, J., Rooney, W.L. and Mullet, J.E. (2018) Sorghum Stem Aerenchyma Formation Is Regulated by SbNAC_D during Internode Development. Plant Direct, 2, e00085. https://doi.org/10.1002/pld3.85

[5] Paterson, A.H., et al. (2009) The Sorghum bicolor Genome and the Diversification 
of Grasses. Nature, 457, 551-556. https://doi.org/10.1038/nature07723

[6] Mindaye, T.T., Mace, E.S., Godwin, I.D. and Jordan, D.R. (2015) Genetic Differentiation Analysis for the Identification of Complementary Parental Pools for Sorghum Hybrid Breeding in Ethiopia. Theoretical and Applied Genetics, 128, 1765-1775. https://doi.org/10.1007/s00122-015-2545-6

[7] CSA (2018) The Federal Democratic Republic of Ethiopia Central Statistical Agency (CSA) Agricultural Sample Survey Report on Area and Production of Major Crops.

[8] Wagaw, K. (2019) Review on Mechanisms of Drought Tolerance in Sorghum (Sorghum bicolor (L.) Moench) Basis and Breeding Methods. Academic Research Journal of Agricultural Science and Research, 7, 87-99.

[9] Seyoum, A., et al. (2019) Evaluation of Sorghum (Sorghum bicolor (L.) Moench) Genotypes for Grain Yield and Yield Related Traits in Drought Prone Areas of Ethiopia. Advances in Crop Science and Technology, 7, 1-10.

[10] Smith, R.T. and Cullis, A.B. (2001) Analyzing Variety by Environment Data Using Multiplicative Mixed Models and Adjustments for Spatial Field Trend. Biometrics, 57, 1138-1147. https://doi.org/10.1111/j.0006-341X.2001.01138.x

[11] Ullis, B.R.C., Mith, A.B.S. and Oombes, N.E.C. (2006) On the Design of Early Generation Variety. Journal of Agricultural, Biological and Environmental Statistics, 11, 381-393. https://doi.org/10.1198/108571106X154443

[12] Chandra, S. (2004) Spatial Analysis of Small Plot Field Trials Using ASReml. ICRISAT.

[13] Singh, F.R.K. and Chaudhary, D. (1977) Biometrical Methods in Quantitative Genetic Analysis. Third Edition, Kalyani Publishers, New Delhi.

[14] Ali, H.I., Mahmoud, K.M. and Amir, A.A. (2012) Estimation of Genetic Variability, Heritability and Genetic Advance in Grain Sorghum Population. American-Eurasian Journal of Agricultural \& Environmental Sciences, 12, 414-422.

[15] Wagaw, K., et al. (2020) Multi-Environment Trial and Spatial Analysis for Yield Performance of Sorghum [Sorghum bicolor (L.) Moench] Hybrids in Dry Lowland Sorghum Growing Areas of Ethiopia. Journal of Plant Breeding and Crop Science, 12, 275-284.

[16] Seyoum, A., et al. (2020) Multi Environment and Spatial Analysis of Early Maturing Sorghum [Sorghum bicolor (L.) Moench] Genotypes in Dry Lowland Areas of Ethiopia. African Journal of Agricultural Research, 15, 278-290. https://doi.org/10.5897/AJAR2019.14495

[17] Tadese, D., Lakew, B. and Taye, G. (2019) Spatial Analysis in Multi-Environment Trials of Malt Barley in Ethiopia. African Crop Science Journal, 27, 515-527. https://doi.org/10.1017/CBO9781107415324.004

[18] Temesgen, M., Alamerew, S., Eticha, F. and Mehari, M. (2015) Genotype X Environment Interaction and Yield Stability of Bread Wheat Genotypes in South East Ethiopia. World Journal of Agricultural Sciences, 11, 121-127.

[19] Yan, W. and Hunt, L.A. (2001) Interpretation of Genotype x Environment Interaction for Winter Wheat Yield in Ontario. Crop Science, 41, 19-25. https://doi.org/10.2135/cropsci2001.41119x

[20] Akter, A., Hasan, M.J., Kulsum, U., Rahman, M., Khatun, M. and Islam, M. (2015) GGE Biplot Analysis for Yield Stability in Multi-Environment Trials of Promising Hybrid Rice (Oryza sativa L.). Bangladesh Rice Journal, 19, 1-8. https://doi.org/10.3329/brj.v19i1.25213

[21] Endalamaw, C., Tadesse, T., Seyoum, A., Gebreyohannes, A. and Nega, A. (2019) GGE Biplot for Grain Yield and, Estimation of Variance Components and Herita- 
bility of Agronomic Traits for Early Maturing Sorghum (Sorghum bicolor L. Moench) Genotypes. Academic Research Journal of Agricultural Science and Research, 7, 266-284.

[22] Kumar, S.R., Shrotria, P.K. and Deshmukh, J.P. (2008) Characterizing Nutrient Management Effect on Yield of Sweet Sorghum Genotypes. World Journal of Agricultural Sciences, 4, 787-789. 